\title{
Quantifying biodiversity in ecosystems with green lacewing assemblages
}

\author{
Bruno Deutsch ${ }^{\mathrm{a}}$, Mihaela PAUlian ${ }^{\mathrm{b}}$, Dominique ThIERRY $^{\mathrm{c} *}$, Michel CANARD $^{\mathrm{d}}$ \\ ${ }^{a}$ Université Catholique de l'Ouest, Institut de Mathématiques Appliquées, 3 place André Leroy, 49000 Angers, France \\ ${ }^{\mathrm{b}}$ Institutul de Cercetari pentru Protectia Plantelor, Bd. Ion Ionescu dela Brad 8, 77592 Bucuresti, Romania \\ c Université Catholique de l'Ouest, IRFA/Centre d'étude et de recherche sur les écosystèmes aquatiques, 44 rue Rabelais, 49000 Angers, France \\ d (retired) 47 chemin Flou de Rious, 31400 Toulouse, France
}

(Accepted 12 January 2005)

\begin{abstract}
Green lacewings are pertinent bio-indicators of an ecosystem's health. An example for detecting temporal changes in crop field biodiversity over a short period by sampling chrysopids is given. Light-trapping collections over ten years near Bucharest (Romania) implied changes in the species assemblages. The main species present were members of the Chrysoperla carnea-complex. They increased from 38 to $72 \%$ of the total Chrysopidae in samples. The faunistic richness (Margalef's index) only decreased by about 9\% of its initial value. Shannon's diversity and Hurlbert's equitability indices showed a high level of biodiversity for an agri-environment. Nevertheless, they decreased significantly by about $45 \%$ over time, attesting to a loss in biodiversity. Statistical analysis by linear and logistic regressions shows that the progressive dominance of the common green lacewings is realistic, and constitutes indication of change in crop field biodiversity.
\end{abstract}

ecological modelling / Chrysoperla carnea / beneficial insect / biodiversity change / agro-ecosystem / Romania

\section{INTRODUCTION}

A high level of biodiversity generally reflects stability of ecosystems; that is, the probability that a system will provide a consistent level of performance over a given unit of time (Naeem and Li, 1997). Appraising the current well-being and sustainability of agricultural ecosystems is now of fundamental importance to scientists and advisors. The ability of agro-ecosystems to remain sustainable needs management to prevent their decline in viability, in turn likely to compromise their future potential and render them unsustainable. It is now possible to quantify accurately various aspects of biodiversity (Thierry et al., 2003), providing a monitoring tool to detect and evaluate changes within a biotope. The present paper aims to demonstrate an example of biodiversity change in an agricultural landscape over a short period. Due to the small number of years studied, an a priori justification of the use of regression models and an a posteriori comparison were performed.

Since 1985, under the authority of the Institute of Plant Protection of Bucharest, a survey of beneficial insects has been undertaken to improve integrated pest management in crops in the Romanian Plain (Paulian, 1996). Numerous collections of insect predators of various crop pests were made, amongst which green lacewings (Insecta: Neuroptera: Chrysopidae) were sufficiently abundant to give a good idea of their actual occurrence in the agri-environment. The experimental procedures used allow comparisons of chrysopid assemblage structure, and thus detection of significant variations between yearly samples.

\section{MATERIALS AND METHODS}

\subsection{Collecting specimens and recording data}

Adult lacewings were collected by means of two light traps operated between mid-March and mid-November (the exact time varying with the year), over six consecutive growing seasons, plus one more season four years later (Tab. I). The two traps were placed 6 metres above the ground and powered with mercury vapour bulbs of 400 and 250 watts. They were both situated within the experimental field station of Baneasa ( $44^{\circ} 03$ ' 00” N / 26 03' 00" E) near Bucharest (Romania), far from any other light source such as household, urban or road lighting that dilute their effectiveness. The environment near the traps varied, but always consisted of perennial crops on one side (orchards and vineyards) and of annual crops on the other side, the nature of which differed every year. Various weeds

* Corresponding author: dominique.thierry@ wanadoo.fr 
Table I. Numbers (N) of green lacewings collected by light traps at Bucuresti-Baneasa, Bucharest vicinity, Romania, and mean frequency Q (\%); $*=$ two traps working.

\begin{tabular}{|c|c|c|c|c|c|c|c|c|c|}
\hline & 1985 & 1986 & $1987 *$ & $1988^{*}$ & $1989 *$ & $1990^{*}$ & 1994 & $\mathrm{~N}$ & $\mathrm{Q}$ \\
\hline Chrysoperla carnea s. l. (Stephens, 1836) & 228 & 386 & 1525 & 894 & 576 & 1230 & 402 & 5241 & 40.7 \\
\hline Chrysopa formosa (Brauer, 1850) & 153 & 602 & 1407 & 1014 & 532 & 667 & 96 & 4471 & 34.8 \\
\hline Chrysopa pallens (Rambur, 1842) & 68 & 114 & 1173 & 169 & 78 & 223 & 33 & 1858 & 14.7 \\
\hline Chrysopa perla (Linnaeus, 1758) & 56 & 74 & 205 & 159 & 123 & 214 & 8 & 839 & 6.5 \\
\hline Cunctochrysa albolineata (Killington, 1935) & 22 & 30 & 16 & 8 & 12 & 23 & & 111 & 0.9 \\
\hline Chrysopa phyllochroma (Wesmael, 1841) & 62 & 8 & 18 & 5 & 4 & 4 & 5 & 106 & 0.8 \\
\hline Dichochrysa prasina (Burmeister, 1839) & & 20 & 12 & 8 & 18 & 28 & 7 & 93 & 0.7 \\
\hline Chrysopa nigricostata (Brauer, 1850) & 12 & 31 & 16 & 12 & 3 & 16 & & 90 & 0.7 \\
\hline Chrysopa abbreviata (Curtis, 1834) & 2 & 3 & 16 & & 2 & & 2 & 25 & 0.2 \\
\hline Nineta flava (Scopoli, 1763) & & & 6 & & 1 & & & 7 & $\varepsilon$ \\
\hline Nineta vittata (Wesmael, 1841) & & & & 3 & 3 & & & 6 & $\varepsilon$ \\
\hline Dichochrysa flavifrons (Brauer, 1850) & 1 & & & 1 & & 1 & 2 & 5 & $\varepsilon$ \\
\hline Chrysopa viridana (Schneider, 1845) & & 3 & & & & 1 & & 4 & $\varepsilon$ \\
\hline Chrysopa dasyptera (MacLachian, 1872) & & 2 & & & & & & 2 & $\varepsilon$ \\
\hline Nothochrysa fulviceps (Stephens, 1836) & & & 1 & & & & & 1 & $\varepsilon$ \\
\hline Total & 604 & 1273 & 4395 & 2273 & 1352 & 2407 & 555 & 12859 & - \\
\hline No. of spp. & 9 & 11 & 11 & 10 & 11 & 10 & 8 & 15 & - \\
\hline Duration of collection (days) & 185 & 192 & $112 \times 2$ & $92 \times 2$ & $133 \times 2$ & $242 \times 2$ & 57 & 1592 & - \\
\hline
\end{tabular}

and other spontaneous vegetation grew on field borders and in other nearby uncultivated areas.

The data were statistically analysed by using Statgraphics Plus for Windows 4.0. We separated the two main groups of green lacewings with respect to their imaginal food requirements: the specimens of the genus Chrysoperla Steinmann which are glyco-palynophagous [noted $x(t)$ at time $t$ ] and the specimens of the genus Chrysopa Leach which are carnivorous [noted $y(t)$ at time $t$ ]. We then considered the proportion of Chrysoperla in the whole green lacewings set

$$
q(t)=\frac{x(t)}{x(t)+y(t)} .
$$

\subsection{Biodiversity assessment}

The biodiversity was appraised by several well-known indices already used by Thierry et al. (2003). We computed (i) Margalef's index, $\mathrm{I}_{\mathrm{M}}$, to characterise the approximate faunistic richness, (ii) the widely used Shannon's diversity index, H', as the relative importance of each collected species and the ratio between the total numbers of species and individuals, and (iii) Hurlbert's equitability index, $\mathrm{E}_{\mathrm{H}}$, which measures the relative heterogeneity of populations, featuring the distribution of the species and specimens occurring in an assemblage and assessing the dominance of the more abundant species. To ascertain the data recorded during a single yearly sampling campaign in each case, we used the Bootstrap method. We calculated annual mean values associated with $(95 \%)$ confidence intervals from 10000 virtual samplings, simulated by randomly picked up sub-samples within a virtual infinite population showing the same distribution of species as the original collection. In the case of the Margalef index, the sub-samples never have more species than the original one but may have fewer. The upper bound of the interval is thus the same as the estimated value of $\mathrm{I}_{\mathrm{M}}$. In order to appraise the possible upper variability of the estimations, the upper bound CT2 was changed in CT2' $=\mathrm{I}_{M}+\left(\mathrm{I}_{\mathrm{M}}-\mathrm{CT} 1\right)$. This means that there is almost the same probability of finding a new species as of missing one among the rarest species of the sample. A classifying process (Cluster Scatterplot) was then applied in order to appraise the proximity of the annual values. Comparisons were made between yearly samples on a common duration of sampling time, namely June, July and August, which comprises more than $89 \%$ of the total captures (Paulian, 1996).

\section{RESULTS AND DISCUSSION}

\subsection{Green lacewing collections}

Table I shows the identity and the numbers of chrysopid specimens collected. Specimen and species numbers collected enabled evaluation of the occurrence of green lacewings in the habitat. Fifteen species occurred, excluding the constituents of the so-called 'common green lacewing' group here referred to as Chrysoperla carnea (Stephens, 1836) sensu lato. This complex of sibling species is made up in Romania of Chrysoperla affinis (Stephens, 1836) [= kolthoffi Navás, 1927, sensu Thierry], Chrysoperla lucasina (Lacroix, 1912) and Chrysoperla carnea sensu stricto (Paulian et al., 1996). These co-occurring sibling species together were dominant. They constituted almost half of the overall green lacewing assemblages during the surveys. Two other species, Chrysopa formosa Brauer, 1850, and Chrysopa pallens (Rambur, 1838), were constant and common. They are abundant elsewhere in parks and orchards, hedges and gardens intensively cultivated by man, and on shrubs and deciduous trees (Zeleny, 1984). Chrysopa perla (Linnaeus, 1758) occurs on shrubs and herbaceous 
vegetation of open and wet biotopes. It also appeared every year; however, it was globally rare, except in 1990 during which its abundance was comparable with that of the arboreal Ch. pallens. The distribution of Ch. perla during the season they were abundant in July — suggested bivoltinism (Volkovich, 1996) of the population. Several other species were captured sporadically, always appearing in low numbers and in some years only. They were, in order of decreasing numerical importance, Cunctochrysa albolineata (Killington, 1935), Dichochrysa prasina (Burmeister, 1839), Chrysopa nigricostata Brauer, 1850, Chrysopa phyllochroma (Wesmael, 1841), Dichochrysa flavifrons (Brauer, 1850), Chrysopa abbreviata (Curtis, 1834), Nineta flava (Scopoli, 1763), Nineta vittata (Wesmael, 1841), Chrysopa viridana (Schneider, 1845), Chrysopa dasyptera (McLachlan, 1872), and Nothochrysa fulviceps (Stephens, 1836). Another species occurred in the biotope but was not recorded during the present study: Chrysopa dubitans (McLachlan, 1887), was not trapped but was swept by hand net; namely, three specimens in 1994 (Paulian and Canard, 2000).

The present evaluation study did not show any decrease in the basic biomass of chrysopids, even if the species richness seemed to have changed. The total numbers of lacewings collected per year indeed fluctuated greatly over the survey period. As the period of trapping was not the same every year, we compared only the parts of samples relative to the summertime, between the beginning of June and the end of September. The catching power of the trap(s) varied according to a ratio of more than 3.8 times between the highest mean collection (137.8 green lacewings per week and per trap in 1987) and the poorest (35.8 per week and per trap in 1985). The factor(s) responsible for such fluctuations are unknown.

The fauna composition showed changes which are of interest. The trend of differences in the balance of species with respect to the kind of feeding regime indicated gradual decrease of the species with carnivorous habits as adults belonging to the genus Chrysopa to the gain of the palyno-glycinophagous ones. These, the common green lacewings, became more and more abundant relative to their mean annual frequency, $\mathrm{Q}$, increasing from 0.38 to 0.72 of the total chrysopid fauna. That is possibly linked to the ability of their larvae to invade many crops despite increasing pesticide applications (Vogt and Viñuela, 2001). There is decrease in the species overwintering as prepupae within the cocoon in the litter and/or in the soil to the gain of those overwintering as adults in reproductive diapause (genus Chrysoperla) and as free-living diapausing larvae (genus Dichochrysa Yang) (Principi, 1992).

\subsection{Comments on methodology and analysis}

The recorded values (Tab. I) show that the data following the year 1985 increased over time. The probability that six consecutive pure random numbers will form an increasing sequence is extremely small (1/720) so that a purely random effect may be rejected. An exact run test gives a $P$-value of 0.025 , having two or less runs up-and-down in that sequence (Lecoutre and Tassi, 1987), so that there will be no change in our conclusion if we include the first year. The same inference occurs with the exact correlation rank Spearman test which gives a $P$-value of 0.0062 or with the exact rank of the Neumann ratio (Madansky, 1988) of which the $P$-value is lower than
0.005. Finally, a linear regression over all the years gives a fairly good result $\left(R^{2}=0.88\right)$ assorted with reasonable normality of the residuals: Shapiro-Wilks $P$-value $=0.06$. Nevertheless, because 1985 is the first year of the period studied and because the following values form a highly structured sequence, it is preferable to split the data into two groups and to focus on the second period. It was not possible to understand why the year 1985 does not belong to that run. There is no evidence of a peculiar weather pattern. Is it because this collecting season was the first measured or was there a change beginning in 1986? Was it an exceptional year or the end of a preceding period of decrease? Whatever the underlying cause, from 1986 to 1994 the six recorded values form an increasingly simple and well-fitted sequence.

Two or three simple models are of interest to fit the data: the classical linear model, the logistic model, and secondarily, the exponential one. The linear model is always suitable as an approximation for any smooth growth over a short period. An alternative model well known in ecology is the logistic one (e.g. Turchin, 2003). Generally such a model involves the number of individuals instead of a proportion. However, it may be viewed mathematically as an approximation of the differential equation describing the evolution of a system, with timedepending variable $q(t)$, to which the relative rate of change, $(\mathrm{d} q / q) / \mathrm{d} t$, is related with the variable $q$ instead of being constant as in the exponential model. A first-order approximation of the rate leads to the logistic equation (Pavé, 1994). We will show below that the logistic model for $q$ may be derived from a rather general differential model for the evolution of $x$ and $y$. The linear model and furthermore the exponential model have the disadvantage of being a priori unbounded when time is increasing, as a limit for long period analysis. We therefore reject the exponential model and only present comparison between the linear and the logistic models. The latter has a realistic $\mathrm{S}$ shape and it is a priori bounded. We emphasize that the aim is not to interpret the value of the coefficient in the model (and eventually the underlying process) but only to show that a homogeneous process is observed. Many elaborated mechanisms have been derived in related literature in order to describe dynamics but due to the few limited data only simple and robust models with few parameters can be considered.

Concerning the logistic model for $q$, it is well known that the relation $q(t)=\frac{K e^{c t}}{1+K e^{c t}}$ with convenient constants $C$ and $K$ is equivalent to the differential equation $\frac{1}{q} \frac{d q}{d t}=c(1-q)$ which may be written

$$
\frac{1}{q(1-q)} \frac{d q}{d t}=c,
$$
if $0<q<1$, with $q(0)=\frac{K}{1+K}$. Using the differentiation rule
we have

$$
d\left(\frac{x}{x+y}\right)=\frac{y d x-x d y}{(x+y)^{2}}
$$

so by substitution we find

$$
\frac{1}{r(1-r)} \frac{d r}{d t}=\frac{1}{x} \frac{d x}{d t}-\frac{1}{y} \frac{d y}{d t}
$$


Table II. Biodiversity indices of the yearly samplings collected in crop fields of Bucuresti-Baneasa, Bucharest vicinity, Romania. Italic types: estimated value, in parentheses: (SD) and in square brackets: [CT1 - CT2].

\begin{tabular}{lcccccccc}
\hline \multicolumn{1}{c}{ Year } & 1985 & 1986 & 1987 & 1988 & 1989 & 1990 & 1994 & Global \\
\hline Richness & 1.26 & 1.40 & 1.20 & 1.17 & 1.39 & 1.15 & 1.11 & 1.49 \\
of Margalef & $(0.09)$ & $(0.06)$ & $(0.06)$ & $(0.07)$ & $(0.09)$ & $(0.09)$ & $(0.08)$ & $(0.07)$ \\
$\quad\left(\mathbf{I}_{\mathbf{M}}\right)$ & {$[0.94-1.26]$} & {$[1.26-1.40]$} & {$[1.07-1.20]$} & {$[1.04-1.17]$} & {$[1.11-1.39]$} & {$[0.89-1.15]$} & $0.95-1.11]$ & {$[1.28-1.49]$} \\
\hline Diversity & 1.64 & 1.41 & 1.33 & 1.2 & 1.27 & 1.28 & 0.9 & 1.36 \\
of Shannon & $(0.03)$ & $(0.03)$ & $(0.01)$ & $(0.02)$ & $(0.02)$ & $(0.02)$ & $(0.04)$ & $(0.01)$ \\
$\quad(\mathbf{H})$ & {$[1.57-1.70]$} & {$[1.35-1.46]$} & {$[1.32-1.36]$} & {$[1.16-1.23]$} & {$[1.22-1.32]$} & {$[1.24-1.32]$} & {$[0.81-0.99]$} & {$[1.34-1.37]$} \\
\hline $\begin{array}{c}\text { Equitability } \\
\text { of Hurlbert }\end{array}$ & 0.74 & 0.58 & 0.55 & 0.51 & 0.52 & 0.55 & 0.41 & 0.5 \\
$\quad\left(\mathbf{E}_{\mathbf{H}}\right)$ & {$[0.028)$} & $(0.016)$ & $(0.012)$ & $(0.015)$ & $(0.017)$ & $(0.021)$ & $(0.026)$ & $(0.009)$ \\
\hline
\end{tabular}

Consider first the Lotka-Volterra model for the populations $x$ and $y$.

$$
\left\{\begin{array}{l}
\frac{d x}{d t}=\alpha x-\beta x y \\
\frac{d y}{d t}=\gamma x y-\delta y
\end{array}\right.
$$

with convenient constants $\alpha, \beta, \gamma, \delta$. By substitution it follows

$$
\frac{1}{q(1-q)} \frac{d q}{d t}=\alpha+\delta-\beta y-\gamma x .
$$

So we can see that with the trivial condition $\beta=\gamma=0$, we can obtain a logistic model for $q$. In the Lotka-Volterra model, that is exactly the case in which there is no cross-correlation between $x$ and $y$ when processes $x$ and $y$ are simple exponential functions of time. However, that is not the only situation which implies a logistic model for $q$.

We focus on the fact that, because of the previous relations (E1) and (E2), the logistic model is equivalent to

$$
\frac{1}{x} \frac{d x}{d t}-\frac{1}{y} \frac{d y}{d t}=c
$$

so that any dynamics of the following patterns

$$
\left\{\begin{array}{l}
\frac{1}{x(t)} \frac{d x(t)}{d t}=f(t) \\
\frac{1}{y(t)} \frac{d y(t)}{d t}=f(t)+c
\end{array}\right.
$$

where $f$ is a function of the variable $t$, or more generally

$$
\left\{\begin{array}{l}
\frac{1}{x(t)} \frac{d x(t)}{d t}=g(t, x(t), y(t)) \\
\frac{1}{y(t)} \frac{d y(t)}{d t}=g(t, x(t), y(t))+c
\end{array}\right.
$$

where $g$ is any function of the three variables $t, x$ and $y$, leads to the logistic model for the proportion $q$.
The 'G-pattern' is the most general model which leads to the logistic function for $q$. However the 'F-pattern' is easy to make clear. It indicates that whatever the environmental influence, supposedly the same in time for $x$ and $y$ (e.g. weather changes), and whatever the initial values for $x$ and $y$, the relative rate of growth of $x$ always has the same advantage over that of $y$. In other words, $x$ profits constantly more than $y$ from the shared environment. The G-pattern supposes a form of symmetry in the interaction between $x$ and $y$ which may be more difficult to conjecture.

Let us examine the relevance of the results arising from mathematical analysis. It is not realistic to imagine that over intermediate time (a few years) an exponential model can be fitted to the growth of a population sensitive to a varying environment, although it may be over a short time (with local approximation corresponding to little variations in the environment) or a long time (averaging effects of consecutive variations in the environment). But when we consider the ratio $q$, changes of exogenous parameters are reduced in the dynamics of the process $q$ which intuitively reflects only the advantage of one population over the second for the benefit of the environment. We demonstrated that a constant and uniform advantage is equivalent to a logistic model for $q$. This seemingly original last statement is a convincing argument to justify a priori the use of a logistic regression in the case of the evolution of a proportion over time, rather than a simple ad hoc fitting. Applications ought to be made in estimation and control of mixed populations in which one species is more easily estimated.

\subsection{Biodiversity}

The values of the biodiversity parameters are shown in Table II. The Margalef's richness and Shannon's diversity indices are lower than in areas without any human-borne pressure on natural resources where they reached, for instance, 2.65 $\left(\mathrm{I}_{\mathrm{M}}\right)$ and $1.52\left(\mathrm{H}^{\prime}\right)$, respectively, in Transylvanian montane forest. Nevertheless, they are considerably greater than the values reported in modern farming agrosystems, sensu Frontier and Pichod-Viale (1900) in which the monoculture crops, the almost complete elimination of trees, and the chemical weedand pest-management have consequent effects on invertebrate biodiversity. For instance, they were $0.92\left(\mathrm{I}_{\mathrm{M}}\right)$ and $0.80\left(\mathrm{H}^{\prime}\right)$, respectively, in vegetable field crops of northern France. 

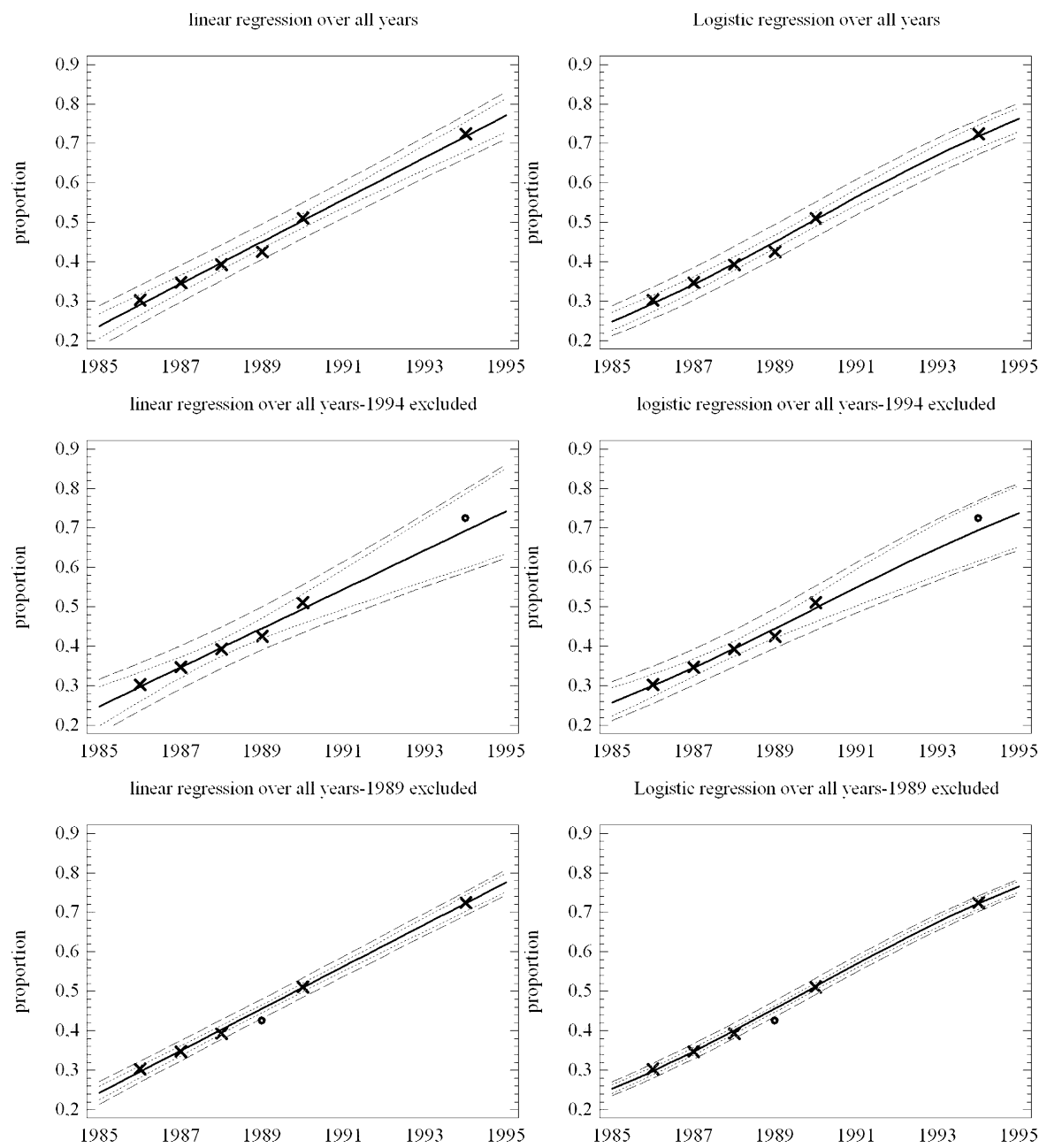

linear regression over all years-1989, 1994 excluded
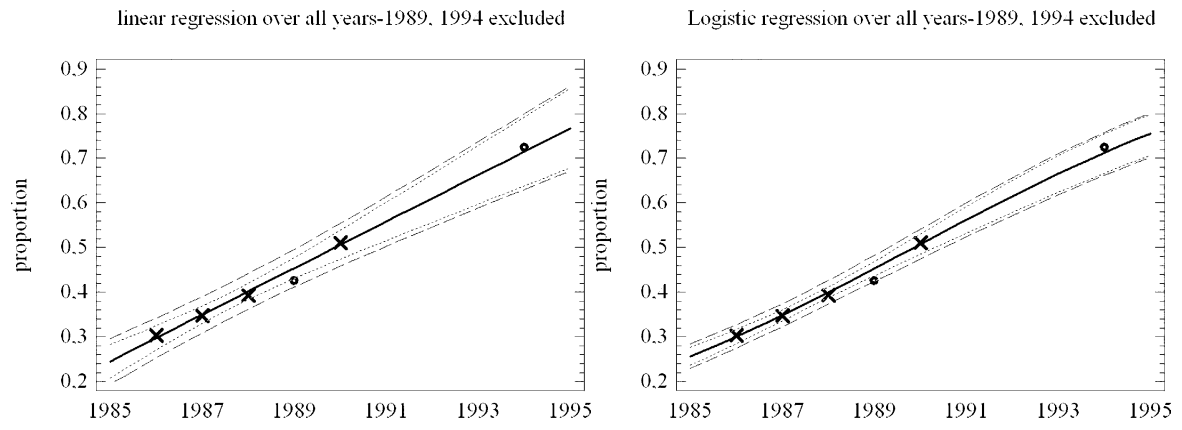

Figure 1. Comparisons between linear and logistic regressions. The outer dotted lines represent confident limits for prediction of single values, inner dotted lines represent confident limits for regression lines. Rings are points which are not used for fitting.

Contrarily, the value of Hurlbert's equitability index $\left(E_{H}\right)$ is of equivalent value between 0.4 and 0.5 , showing an average dominance of species (see comments on these examples in Thierry et al., 2003).

Concerning the changes observed during the survey, the diversity and equitability varied symmetrically: during the four first years, they decreased regularly, after which they remained roughly constant for the following two years. But four years later, the two parameters had strongly decreased. A group of species (Chrysoperla) remained the most characteristic of the biotope, or at least, declined less than the others. As they have demonstrated their ability to become commonplace members of various cultivated areas in many parts of the world (Duelli, 2001), they have much a better chance of survival (Stary and Pike, 1998).

\subsection{Comparison between numerical fittings}

As noted earlier, we present only comparison between the linear model and the logistic one over the years 1986-1990 and 1994: the formula 'all years' indicates these years. The analysis of data concerning the proportion $q(t)$ produces some interesting results. The small amount of data is balanced by the very good quality of the fitting to the model finally selected (Fig. 1). 
Table III. Characters of the various regression analyses (see text).

\begin{tabular}{lll}
\hline A & & \\
\hline regression & linear & logistic \\
$R$-squared & 0.992 & 0.993 \\
RMSE & 0.0122 & 0.0114 \\
$P$-value for slope & 0.0000 & 0.0000 \\
estimated Kolmogorov $P$-value & 0.83 & 0.64 \\
ShapiroWilks $P$-value & 0.14 & 0.030 \\
Kurtosis $P$-value & 0.13 & 0.044
\end{tabular}

\begin{tabular}{lll}
\hline B $\quad$ Regressions over all years, excepted 1994 & \\
\hline regression & linear & logistic \\
$R$-squared & 0.973 & 0.979 \\
RMSE & 0.0167 & 0.0156 \\
estimated Kolmogorov $P$-value & 0.97 & 0.83 \\
ShapiroWilks $P$-value & 0.88 & 0.55 \\
Kurtosis $P$-value & 0.54 & 0.28 \\
relative forecast error for $t=1994$ & $4.34 \%$ & $4.10 \%$
\end{tabular}

\begin{tabular}{lll}
\hline C Regressions over all years, excepted 1989 & \\
\hline regression & linear & logistic \\
$R$-squared & 0.9987 & 0.9992 \\
RMSE & 0.0131 & 0.0127 \\
estimated Kolmogorov $P$-value & 0.99 & 0.98 \\
Kurtosis $P$-value & 0.59 & 0.61
\end{tabular}

\begin{tabular}{lll}
\hline D $\quad$ Regressions over all years, excepted $1989 \&$ & 1994 & \\
\hline regression & linear & logistic \\
$R$-squared & 0.9943 & 0.9975 \\
RMSE & 0.0129 & 0.0123 \\
estimated Kolmogorov $P$-value & 0.946 & 0.92 \\
relative forecast error for $t=1994$ & $1.26 \%$ & $1.6 \%$ \\
\hline
\end{tabular}

The main fact is that in contrast with the chaotic growth of each of the two groups of species studied, their relative proportion (or more precisely the proportion of one over both) indicates structured change.

As the data recorded after 1985 increased with time, we first compared the two models for all these years (Tab. IIIA). In the following comparisons, the RMSE values (Root Mean Square of Errors) defined by $\sqrt{\frac{1}{n} \sum_{1}^{n}(\text { predicted }- \text { observed })}$ are given for each fitting. In each case it was calculated over all the years. Various tests were done to evaluate the normality of residuals.

The logistic model may have a slight advantage, though the normality of residuals is less assessed. In order to appreciate the accuracy of the fittings we analysed the data with each year $t=1986,1987,1988,1989,1990$ and used the relative result to evaluate the value for $t=1994$ (Tab. IIIB). The logistic again displayed a slight advantage with slightly better fitting and a better forecast. The graphs that the confidence limits for the estimated curves are closer in the case of logistic regression.
The analysis of the studentised residuals shows that the year $t=1989$ is unusual, and it is tempting to fit the data without that year in both cases. The one in which $t=1994$ is included in the fitting and the case in forecasted is shown in Table IIIC. Without the years $t=1989$ and $t=1994$ (Tab. IIID), the value for 1994 is very well forecast, featuring so that $t=1994$ is not an influential point. The graphs again show closer confidence limits in the case of logistic regression.

\section{CONCLUSION}

Few data are available to appraise relationships between man-linked perturbation (such as accelerating urbanisation and intensive management of crop fields) and biodiversity (Swift et al.,1996). Previous work has not given any evidence that biodiversity decreases significantly with the vegetational diversity in suburbs (e.g. Bozsik, 1992), or in a maize culture environment (e.g. Szentkirályi, 1989), or with intensification of human impact (e.g. Duelli et al., 1999). The above observations of changes manifested in the agri-environment near Bucharest provide a good illustration of the relevance of the logistic model to fit both the evolution of a ratio and the development of the changing constitution of a faunal group. However, it would be interesting to have a longer series on a larger scale to strengthen and confirm comparison in Romania. Concerning the actual factor(s) responsible for the phenomenon, as well as its ubiquity, only further studies might give a response.

The data are well fitted by linear and logistic regression with a slight advantage for the logistic one. Various controls were carried out which confirm the robustness of the fitting. Conversely, the present statistical analysis shows a coherent structure of the series, strengthening the possibility of extrapolating the model for future years, despite the low numbers of observations.

Such a preliminary study constitutes a tentative statement useful for estimating and understanding evolution within a cropping environment. Green lacewings appear to be suitable biological indicators of the health of ecosystems, and their changes endorse the importance of preventing environmental damage within the agricultural landscape, in the interest of promoting development of both biological crop protection and sustainable agriculture. A sustainable future cannot be assured without the conservation of biodiversity (Boller and Poehling, 2003; Pimm and Brown, 2004).

Acknowledgements: A shorter version of the present work was presented as a poster in the Third International Plant Protection Symposium at Debrecen University, Debrecen, Hungary, 15-16 October 2003: From Ideas till Implementation. Challenge and Practice of Plant Protection in the Beginning of the 21st Century. The authors are grateful to Dr T.R. New (Bundoora, Victoria, Australia) for kindly improving and checking English in the manuscript, to Dr $\mathrm{X}$. Le Bris and to the anonymous reviewers for helpful comments.

\section{REFERENCES}

Boller E.F., Poehling H.M. (2003) Functional biodiversity and agro-ecosystems management, A new IOBC/WPRS project, IOBC/wprs Bull. 26, 17-20. 
Bozsik A. (1992) Influence of vegetational diversity on chrysopid assemblages, in: Proceedings of the Fourth European Congress of Entomology and the XIII, Internationale Symposium für die Entomofaunistik Mitteleuropas, Gödöllö, Hungary, 1991, Hungarian Natural History Museum, Budapest, Hungary, pp. 256-260.

Duelli P. (2001) Lacewings in field crops, in: McEwen P.K., New T.R., Whittington A.E. (Eds.), Lacewings in the Crop Environment, Cambridge University Press, Cambridge, UK, pp. 158-171.

Duelli P., Obrist M.K., Schmatz D.R. (1999) Biodiversity evaluation in agricultural landscapes: above-ground insects, Agr. Ecosyst. Environ. 74, 33-64.

Frontier S., Pichod-Viale D. (1990) Écosystèmes: Structure, Fonctionnement, Évolution, Masson, Paris.

Lecoutre J.P., Tassi P. (1987) Statistiques Non-paramétriques et Robustesse, Economica, Paris, 455 p.

Madansky A. (1988) Prescriptions for Working Statisticians, SpringerVerlag, New York, 295 p.

Naeem S., Li S. (1997) Biodiversity enhances ecosystem reliability, Nature 390, 507-509.

Paulian M. (1996) Green lacewings from southeast of the Romanian Plain, as recorded by light-trapping (Insecta: Neuroptera: Chrysopidae), in: Canard M., Aspöck H., Mansell M.W. (Eds.), Pure and Applied Research in Neuropterology, Proceedings of the Fifth International Symposium on Neuropterology, Cairo, Egypt, 1994, Sacco, Toulouse, pp. 197-202.

Paulian M., Canard M. (2000) Green lacewings new to the Romanian fauna (Neuroptera: Chrysopidae), Entomofauna 21, 249-250.

Paulian M., Canard M., Thierry D., Cloupeau R. (1996) Les Chrysoperla Steinmann de Roumanie (Neuroptera: Chrysopidae), Ann. Soc. Entomol. Fr. (N.S.) 32, 285-290.

Pavé A. (1994) Modélisation en Biologie et en Écologie, Aleas, Lyon, $560 \mathrm{p}$.

Pimm S.L., Brown J.H. (2004) Domains of Diversity, Science 304, 831833.
Principi M.M. (1992) Lo stato di diapausa negli insetti ed il suo manifestarsi in alcune specie di crisopidi (Insecta: Neuroptera) in dependenza dell' azione fotoperiodica, Atti Accad. Sci. Istit. Bologna, Rendiconti Serie 14 (1990-1991) 8, 79-116.

Stary P., Pike K.S. (1998) Uses of beneficial insect diversity in agroecosystem management, in: Collins W.W., Qualset C.O. (Eds.), Biodiversity in Agroecosystems, CRC Press LLC, Boca Raton, FL, USA, pp. 49-67.

Swift M.J., Vandermeer J., Ramakrishnan P.S., Anderson J.M., Ong C.K., Hawkins B.A. (1996) Biodiversity and agrosystem function, in: Mooney H.A. et al. (Eds.), Functional Roles of Biodiversity: a Global Perspective, John Wiley and Sons Ltd, Chichester, New York, Brisbane, Toronto, Singapore, pp. 262-298.

Szentkirályi F. (1989) Aphidophagous chrysopid and hemerobiid (Neuropteroidea) subguilds in different maize fields: influence of vegetational diversity on subguild structure, Acta Phytopath. Entomol. Hung. 24, 207-211.

Thierry D., Deutsch B., Paulian M., Villenave J., Canard M. (2003) Quantifying biodiversity in ecosystems by green lacewing assemblages. I. A valuable method to do (Insecta: Neuroptera: Chrysopidae), in: Kövics G.J. (Ed.), From Ideas to Implementation, Challenge and Practice of Plant Protection in the Beginning of the 21st Century, Debrecen University, Debrecen, Hungary, pp. 246-247.

Turchin P. (2003) Complex Population Dynamics: a Theoretical / Empirical Synthesis, Princeton University Press, Princeton, NJ, 456 p.

Vogt H., Viñuela E. (2001) Interactions with plant management strategies. Effects of pesticides, in: McEwen P.K., New T.R., Whittington A.E. (Eds.), Lacewings in the Crop Environment, Cambridge University Press, Cambridge, UK, pp. 357-366.

Volkovich T. (1996) Effects of temperature on diapause induction in Chrysopa perla (Linnaeus) (Insecta: Neuroptera: Chrysopidae), in: Canard M., Aspöck H., Mansell M.W. (Eds.), Pure and Applied Research in Neuropterology, Proceedings of the Fifth International Symposium on Neuropterology, Cairo, Egypt, 1994, Sacco, Toulouse, pp. 259-267.

Zeleny J. (1984) Chrysopid occurrence in West-Palearctic temperate forests and derived biotopes, in: Canard M., Séméria Y., New T.R. (Eds.), Biology of Chrysopidae, Dr W. Junk, The Hague, pp. 151-160. 